\title{
Developmental dyslexia and vision
}

This article was published in the following Dove Press journal:

Clinical Ophthalmology

13 May 2013

Number of times this article has been viewed

\section{Patrick Quercia' \\ Léonard Feiss ${ }^{2}$ \\ Carine $\mathrm{Michel}^{3}$}

'Department of Ophthalmology, University Hospital, Dijon, France; ${ }^{2}$ Office of Ophthalmology, Beaune, France; ${ }^{3}$ University of Burgundy, Dijon, INSERM UI093, Cognition, Action et Plasticité Sensorimotrice, Dijon, France
Correspondence: Patrick Quercia I5 rue du Clair Matin F-2 I200 Beaune, France

Tel +33380246874

Fax +333802 4II 39

Email docteur.quercia@neuf.fr
Abstract: Developmental dyslexia affects almost $10 \%$ of school-aged children and represents a significant public health problem. Its etiology is unknown. The consistent presence of phonological difficulties combined with an inability to manipulate language sounds and the grapheme-phoneme conversion is widely acknowledged. Numerous scientific studies have also documented the presence of eye movement anomalies and deficits of perception of low contrast, low spatial frequency, and high frequency temporal visual information in dyslexics. Anomalies of visual attention with short visual attention spans have also been demonstrated in a large number of cases. Spatial orientation is also affected in dyslexics who manifest a preference for spatial attention to the right. This asymmetry may be so pronounced that it leads to a veritable neglect of space on the left side. The evaluation of treatments proposed to dyslexics whether speech or oriented towards the visual anomalies remains fragmentary. The advent of new explanatory theories, notably cerebellar, magnocellular, or proprioceptive, is an incentive for ophthalmologists to enter the world of multimodal cognition given the importance of the eye's visual input.

Keywords: reading, ocular motility, dyslexia, neglect, spatial representation

\section{Introduction}

Reading is certainly the most complex oculomotor activity that modern humans use daily. The processing involved is classically separated into lower and higher levels. The first corresponds to the different steps involved in the ocular capture of the word's image, which is the start of cerebral analysis in the occipital cortex. The second represents the different cognitive phenomena that permit the identification of and then represent and make sense of the word just read. The constant interdependence between these phenomena, notably during the oculomotor phase of reading, makes this separation artificial. $^{1}$

Nearly $10 \%$ of school-aged children are unable to acquire fluid and automatic reading skills due to developmental dyslexia. ${ }^{2}$ For the British Dyslexia Association, developmental dyslexia is:

A specific learning difficulty that mainly affects the development of literacy and language, characterized by difficulties with phonological processing, rapid naming, working memory, processing speed, and the automatic development of skills that may not match up to an individual's other cognitive abilities. ${ }^{3}$

It differs from acquired reading difficulties that may occur in the presence of brain damage, notably vascular or traumatic (for example, hemianopic dyslexia in patients 
with homonymous visual field defect, or neglect dyslexia associated with right lesions of the temporoparietal junction areas).

Developmental dyslexia is a clinical diagnosis. It is based on a strategy of successive tests whose exact composition depends on the language of the child, but whose general pattern is always identical. It starts with the realization of the Wechsler Intelligence Scale for Children, which irrefutably determines the normalcy of the child's intelligence quotient and provides an indication of overall intellectual function. A comprehensive test of leximetry follows; it consists of time-limited reading of a text without a precise meaning, using words of varying difficulty that are found infrequently, and can include many potential language uncertainties. The test determines a reading age, which is then compared to the individual's chronological age; the dyslexic child shows a minimum delay of 18 to 24 months (or -2 standard deviations). The subsequent tests will explore the different components of reading in order to understand where the difficulties in decoding written text lie. There are three types of tests:

1. Reading of a word list: the child is presented a list of regular words, irregular words, and pseudowords, for which decryption does not require any particular point of reference or precise knowledge. This test provides an initial indication of a child's weaknesses in reading (decoding) a written text.

2. Meta-phonological tests: these tests assess phonological awareness through the representation and manipulation of sounds (for example, segmentation; comparison or elimination of phonemes).

3. Visual tests: some seek to evaluate the child's visual abilities for implementation of the orthographic lexicon (eg, comparison of almost identical letter sequences such as QUE, QVE, or EQU and identification of identical objects with variable orientation on a standard A4 sheet). Others aim to assess the possibilities of visual-motor integration (eg, create copies of drawn shapes; perform recognition of a specific form within a group of very similar forms; engage in the reproduction of forms under very precise circumstances).

Though it is the subject of a vast amount of research, the origin of developmental dyslexia remains undetermined. The successive psychological, sociological, or educational explanations of the past 30 years are at most now considered aggravating factors. They have been replaced by several theories concerning phonological, magnocellular, cerebellar, or even proprioceptive deficits that might be of genetic origin. ${ }^{4,5}$ Certain hypotheses seem to be reinforced by the discovery of anatomical or functional particularities in some cortical areas of the dyslexic brain, though we are currently unable to clearly distinguish the causes from the consequences. ${ }^{6}$ While recognizing the significant heterogeneity of the dyslexic population, researchers classically refer to three types of clinical dyslexia: ${ }^{7}$

1. Surface dyslexia: the difficulty in recognizing the visual form of written words, especially if they are irregular;

2. Phonological dyslexia: primarily an inability to manipulate language sounds and to perform grapheme-phoneme conversion with particular difficulty for separating the component sounds of words or for being tested with nonsense words ("cortan," for example); and

3. Mixed dyslexia: allies both classes and is the most frequently occurring.

For all three classes, there is a large consensus concerning the constant presence of phonological disorders, attention deficits, and oculomotor anomalies - the latter being the most often considered as secondary to difficulties of cognitive analysis of language. ${ }^{8}$

The recognition and treatment of learning disorders has become a major sociological issue around which the medical and legislative spheres are currently organizing. Ophthalmologists may not remain indifferent when taking into account the fundamental role of vision in reading as well as its dominant role in certain forms of dyslexia. The presence of $5 \%$ to $10 \%$ of dyslexics in the school-aged population has led to the presumption that the needs for care in this area will increase. ${ }^{9}$

\section{Materials and methods}

The proposed data are extracted from a review of the scientific literature accumulated during the last decade. A PubMed search was performed, searching for literature from the years 2000-2012, using the following keywords: binocular coordination and dyslexia, dyslexia and eye movements, vision and dyslexia, dyslexia and neglect, as well as space representation and dyslexia. We included publications whose work has been confirmed by subsequent studies, without excluding publications that are original and form a logical basis for currently accepted concepts pertaining to dyslexia. When several publications addressed the same subject, which was rarely the case, the cited publication was the one that was published first, unless it was followed by research involving larger groups of subjects - in this case, data 
from several publications are cited. Additionally, a certain number of important papers, published between 1985 and 2000, were selectively reviewed for this work. After describing the low-level and high-level processes used when a normal subject reads, we then present the oculomotor and visual characteristics of dyslexia. We continue with the characteristics of attention, visual attention, and spatial representation in these children. Finally, we present the visual treatments proposed for this dysfunction.

\section{Low-level and high-level processing in reading}

When reading a text, the eyes perform a series of ballistic saccades during which no visual information is processed. ${ }^{1}$ During saccades, the axes do not remain parallel; the eye in abduction has a tendency to move further than the eye in adduction. ${ }^{10}$ Generally, the amplitude of saccades covers an average of seven characters (Arial 12), has little dependence on the reading distance, and seems to be mainly regulated by word length and by the spatial interval between them. ${ }^{11}$ Saccades are interrupted by episodes of foveal fixation that allow for the decoding of words and the preparation of the next saccade. The fixation time is on the order of 250 milliseconds ( $\mathrm{ms}$ ). During this period, the position of the two eyes can be crossed, the left eye being more to the right and slightly above the right eye. ${ }^{12}$ This phenomenon is more pronounced before age $12 .{ }^{13}$ Minimal movements that robustly solicit vergence capacities are always needed to ensure effective fusion, respecting the rules of disparity in the center of Panum's area. Some words are skipped, and sometimes fixation takes place between two words. ${ }^{13}$ The visual information processed during fixation, which defines the "perceptual span," has an asymmetrical topography with relation to the point known as "center of gravity" of the word. In general, the span is four letters to the left and may go up to more than ten letters to the right. ${ }^{14}$ The span may correspond to several short words. The span physically exceeds the $2^{\circ}$ angle of the fovea and must involve the parafoveal zone.

The center of gravity is shifted to the left in cases of monocular vision and towards the center if the vision is binocular. The probability of fixation on the end of a word, even if the word is long, is almost zero. ${ }^{15}$ The strategy employed for saccades and fixations is not constant and depends on the morphology of the text, the acquired reading level, as well as certain linguistic, attention, and visual-motor factors. ${ }^{14}$ The normal adult reader has an average reading pace of a text of 200 to 300 words per minute. ${ }^{16,17}$
Visual attention has to be constantly maintained since the reader must interpret identical symbols with different meanings depending on their orientation (for example, $b$ and $\mathrm{p}$ ). Similarly, a word having the same composition of letters may have a different meaning depending on the context (for example, the word glass in "the carved pieces of glass were placed in the glass cupboard"). Semantic processing at the cortical level will detect this difference.

Several models have been proposed to try to explain the interface between words seen on a page and the low-level processes that enable the integration of written text. One of the oldest models is the one proposed by Morrison ${ }^{18}$ that involves two processes from the beginning of decoding a word: first, binocular fixation, which combines oculomotor activity and visual perception to achieve binocular fusion, occurs; second, an intense attentional focalization on the word, essentially a cognitive process, takes place. Initially, the fixation point and the attentional focalization are located at the same place in the word and decoding can begin. When decoding has reached a sufficient level, the focalization moves to the next word even though the eyes do not change the axis of fixation. During this movement, a process of decoding the word $n+1$ begins in the parafoveal area and a saccade is programmed. This expected parafoveal preview allows for increased reading speed and for skipping some words if decoding is sufficiently clear. The saccade is then programmed to word $n+2$, which receives binocular fixation and attentional focalization at the same point. The process continues in a serial fashion for the following words. Although the overall pattern remains valid to this day, the model does not explain a mechanism for the choice of target during saccades, especially during refixations and regressions.

Another more recent model, E-Z Reader 7, attempts to complete Morrison's model. Described by Reichle et al, ${ }^{19}$ it dissociates the programming of saccades from the displacement of focalization and emphasizes the possibility of interference from lexical factors at the highest cognitive level. These authors separate programming of saccades into a labile phase that can be suppressed to allow for an oculomotor adjustment and a nonlabile phase that is impossible to cancel due to the imperative nature of the saccade. At the end of the second phase the word is identified, causing a shift in attention to the next word. This model would better reflect the reality of reading since it allows a reader to adapt strategies for difficult decoding or for words frequently seen, and thus easily identified. In the first case, the labile phase would allow a regressive saccade, while in the second case, skipping a word to go directly to the next one would be possible. 
In contrast to these two models, which propose sequential displacement of attention (word by word), other authors propose reading control through an "attention gradient" wider than the parafoveal area. ${ }^{20}$ This attention window as proposed by the Saccade generation With Inhibition by Foveal Targets (SWIF) model, would better explain the progressive and regressive saccades and the ability to decode words when they are placed to the left of the point of fixation..$^{21,22}$

Higher-level cognitive processes start at the moment of initiation of the identification of characters read in prelexical form. The cortical area involved and designated as the visual word form area, was clearly identified with functional magnetic resonance imaging (f-MRI), and is located near the left lateral occipital-temporal sulcus, on the border of the fusiform gyrus, between the areas of identification of faces and places. ${ }^{23}$ This area does not respond to other stimuli, notably spoken words. It has characteristics of perceptual invariance (it responds in the same way to lowercase and uppercase letters), localization, and responds in accordance with language or with the type of writing, whatever the direction of reading. This area obeys a hierarchical neural organization; neurons in the posterior area interpret fragments of letters and letters, while the more anterior neurons interpret words. It responds only to known forms of writing and is therefore the result of a learning process. A lesion will result in total, uncomplicated alexia in adults, but in young children is accompanied by some compensation in the same area of the right lobe. ${ }^{24}$ For Dehaene et al, ${ }^{24}$ reading would not be the product of a specific phylogenetic evolution of the human brain, but is rather the result of a neuronal recycling from an area of the brain that evolution has dedicated to the recognition of certain forms, notably intersections of straight lines or curves. In other words, the brain would not have evolved to allow reading, but humans would have invented the characters for reading in a particular way because their brains had already put in place a system for decoding specific features. ${ }^{25}$

Neural circuits that permit semantic identification of words are much less known and are subjects of controversy. ${ }^{26}$ Magnetoencephalographic recordings of cortical networks activated during reading show that $250 \mathrm{~ms}$ after retinal capture of the activated regions, primarily the temporoparietal region, these networks have nothing more to do with visual activity; they activate equally with both written and spoken words, and represent areas of linkage between the written word and representations of sound and meaning. The temporal-occipital area thus appears to be the last purely visual high-level area involved in reading a word. ${ }^{27}$
Cognitive psychology interprets cortical phenomena using a two-route model with a phonological route and a direct route. ${ }^{28}$ In the first, the word is treated analytically according to the rules of the grapheme-phoneme conversion. In the second, the components of the word are processed in parallel and activate the orthographic representation of the word within an orthographic lexicon that the reader has created using the phonological route the first time he or she encountered the word. The two channels are indispensable and are constantly used during the reading of a text. The direct route allows for rapid reading and for the understanding of words already encountered and whose meaning has been clearly identified, particularly if the words are irregular and do not fit the usual rules of grapheme-phoneme conversion. The phonological route is essential in order to read new words or nonsense words created artificially that are used to test phonological capacities. ${ }^{29}$

For both high-level and low-level processing, we have to keep in mind that the proposed models are theoretical, and are thus subject to constant revision. Though based on the logic derived from scientific observation, these models do not yet correspond to a tangible reality. They partially obey the dictum "it happens as if." Current knowledge must therefore be regarded as transient, incomplete, and requiring further research. Nevertheless, the present level of knowledge is sufficiently robust to be of high interest to the therapist. All authors agree that the visual characteristics of low-level processing and linguistic processing are intimately interlinked in the control of saccades. The debates mainly concern the manner in which visual-motor and cognitive elements cooperate to program eye movements, as well as the use of a beam or of an attention gradient. ${ }^{30,31}$

\section{Eye movements in dyslexia}

The strategy used by the dyslexic in reading a text differs profoundly from that used by the normal reader. Research undertaken in this area does not yet distinguish whether the oculomotor disorder is primary or secondary to the cognitive difficulties of decoding, or if it is a mixed phenomenon, which is possibly different from one dyslexic to another.

The number of fixations for the dyslexic individual is significantly increased (approximately twofold), and this difference is more pronounced for long words and for less common words. ${ }^{8}$ This increase is due, in part, to more frequent regressive saccades, but is primarily the result of more numerous progressive saccades. When a word requires a single fixation, it is $60 \mathrm{~ms}$ longer on average for dyslexics, whereas in case of multiple fixations, each is increased by 
$50 \mathrm{~ms}$ on average. ${ }^{32}$ This might reflect a difficulty in entering the orthographic lexicon, but also a slowdown in the early phase of visual decoding according to the E-Z Reader model. For Hawelka et al, ${ }^{33}$ who studied fixation strategies in a population of dyslexic adults and who tried to show a link with this model of reading, these particular temporal characteristics reflect the first hypothesis, and is therefore not an expression of a bad localization of fixation. However, proponents of a model that implicates a deficit in low-level processing or a problem posed during visual-attentional processing of serial letters focus more on the visual decoding deficit. ${ }^{34,35}$ Certain studies involving purely visual detection tasks in dyslexics without the intervention of linguistic elements, seem to leave less room for the idea of an alteration of the first phase of low-level processing. ${ }^{36,37}$

The location of the first fixation seems less related to the length of the word, as is the case in the normal reader with a tendency to shift fixation to the left for long words. ${ }^{38,39}$ For common words, there is little difference for the exact location of first fixation when comparing the dyslexic to the normal reader. The number of words skipped is massively reduced to a rate of one word, while the usual rate is three words out of ten in the normal reader. ${ }^{39,40}$ The slowdown in phonological decoding, in provoking a delay in the shift of attention to the next word, could be the cause - the labile phase being, to some extent, erased by the delay.

The loss of parallelism between the two ocular axes during horizontal saccades, a physiological phenomenon first in divergence then in convergence at the end of the saccade, occurs differently in dyslexics. This has been found both in testing with a simple lighted target or when reading isolated words. ${ }^{41}$ This phenomenon is even more exaggerated and irregular when reading a difficult text. The position of the two eyes at the end of the saccade is more uncertain, forcing the child to use more difficult micromovements of vergence, and requiring more attention, though with increased fatigue, to obtain good quality fusion. ${ }^{42}$

The stability of binocular fixation during macular decoding has been implicated in dyslexics. Cornelissen et $\mathrm{al}^{43}$ demonstrated support for this hypothesis by having dyslexics read a list of words using monocular then binocular vision, and the authors found better performance when individuals with dyslexia read with one eye occluded. Although the authors did not find any difference in the possibility for convergence in dyslexics, they proposed to try improving individuals with dyslexia's reading using brief periods of monocular occlusion. This idea was taken up by Stein et al, ${ }^{44}$ whose goal was to create a strong ocular dominance during reading with occlusion over a period of 9 months. With this strategy, the authors obtained a significant increase in reading skills, but did not find that ocular dominance test results were different from the control group. This lack of dominance has been confirmed by other studies. ${ }^{45}$ Stein et $\mathrm{al}^{44}$ also found that during examination with the synoptophore, $64 \%$ of dyslexics demonstrated a rather particular form of convergence insufficiency present only for macular grids of $<3^{\circ}$, even though the participants' capacities for convergence were normal when using larger grids. ${ }^{7}$ For Stein et al, ${ }^{44}$ this implies that an oculomotor dysfunction appears during the macular fixation of letters within a word. ${ }^{46}$ A subsequent study, done with lighted targets in order to study the magnitude of convergence as well as the quality of saccades and of fixation, revealed both global convergence difficulties and a mediocre quality of fixation at the end of saccades. ${ }^{47} \mathrm{~A}$ search in 26 dyslexics for a correlation between the level of phonological deficits and oculomotor abnormalities suggested that ocular dysfunction does not only result from language problems. Other studies have concluded with the existence of anomalies in the accommodation/convergence ratio in dyslexics. ${ }^{48}$ For some, these conclusions justify orthoptic reeducation of these children, although to date, no formal evidence confirms this finding. ${ }^{49}$ On the other hand, this hypothesis seems justified in cases of reading disorders in the absence of dyslexia. ${ }^{50}$

The convergence of dyslexics has also been studied in relation to postural control. Kapoula and $\mathrm{Bucci}^{51}$ have shown that postural stability, in both dyslexics and normal readers, is improved as soon as convergence is stimulated by reducing the fixation point distance. The effect is, however, lower in dyslexics, but can be improved by stimulating the convergence dynamically during the fixation of an approaching object. This notion of difficulty in the static maintenance of convergence is found when clinically examining the dyslexic for proprioceptive disorders associated with postural deficiency syndrome. If the convergence test is started at a good distance and the object is slowly approached, there is a constant difficulty in maintaining the angle of convergence among this population. ${ }^{52,53}$ Postural treatment, with the goal of modifying ocular and general proprioceptive signals, significantly improves the convergence of dyslexics. ${ }^{54}$

One single study, justified by the discovery of different neurological mechanisms for ocular convergence and divergence, examined this concept in a population of dyslexics compared to normal readers. The study results demonstrated a difference between dyslexics and normal readers, even though the capacity for convergence, both far 
and near, seemed not to differ in the two groups. ${ }^{55}$ These results are particularly important to consider when setting up a program for orthoptic reeducation. The frequency of saccades resulting in crossed fixation in the normal reader (requiring a priori, control of divergence just as much as convergence) can start at $8 \%$ and reach almost $50 \%{ }^{56}$

\section{Visual parameters in dyslexia}

Fluid reading requires rapid processing of visual information, both spatial (the arrangement of letters, graphemes, morphemes, and words), and temporal (the sequence of graphemes and words in a specific order). The assumption that the magnocellular system is responsible in the development of dyslexia has led to many studies that looked for anomalies in perception of visual information of low contrast, low spatial frequency, and high temporal frequency in dyslexic subjects. ${ }^{57,58}$ This system, present in the peripheral retina and specialized in the detection of movement and position, does preferentially use this type of information. The magnocellular system, therefore, supposedly contributes to the rapid integration of visual information during reading by allowing efficient processing of spatial and temporal data. This system could thus intervene indirectly in the control of ocular saccades. It could also play an equivalent role for auditory information. ${ }^{59}$

This theory was proposed following the discovery of postmortem abnormalities in ganglion cells of the magnocellular system in the lateral geniculate bodies of dyslexics (smaller cells and disorganized cell layers). ${ }^{4,60}$ The presence of smaller cells suggests the possibility of slower axonal conduction, making rapid transmission of visual information difficult, especially when there is a series of well defined steps as in, for example, decrypting a word. ${ }^{61}$ Note that similar anomalies were also found in the thalamic cells of the medial geniculate area, active in the processing of auditory information, and it has been shown that this processing time is abnormal in dyslexics. ${ }^{62} \mathrm{~A}$ more general theory, involving the rapid processing of sensory information of any kind, is also proposed. ${ }^{63}$

Several authors have uncovered evidence suggesting impairment of the magnocellular system. This evidence includes:

1. The presence of increased latency and decreased amplitude of visual evoked potentials in $40 \%$ to $60 \%$ of dyslexics with moving stimuli and low contrast. This difference decreases with age, and suggests delayed development since it tends to disappear in adolescence. ${ }^{64}$

2. The alteration of the detection thresholds of low contrast, especially when determined with the flicker test. ${ }^{65,66}$ Of note, these deficits of visual contrast are not necessarily present in surface dyslexia. ${ }^{67}$ The loss of contrast sensitivity found in dyslexics is still quite low, as most textbooks are written with characters that have a contrast close to $100 \%$ on the background of white printing paper.

Magnocellular impairment could be involved in the difficulty of separating close stimuli, a problem present in dyslexics outside of reading, such as capturing images of points. ${ }^{68}$ It affects the temporal more than the spatial component. ${ }^{69}$ For Hari et al, ${ }^{70}$ this could be due to a difficulty in disengagement of attention vis-à-vis stimuli. An additional component might be the difficulty to quickly discern visual changes such as those that may be encountered in a series of letters presented repeatedly in random order. ${ }^{71}$

The discovery of visual contrast deficits and the difficulties in assessing the speed of mobile stimuli has led certain authors to propound the magnocellular hypothesis. ${ }^{72}$ Irrespective of the heterogeneous experimental conditions (notably in terms of age and comorbidities), disagreement with this hypothesis might stem from the fact that magnocellular dysfunction is only found in certain subtypes of dyslexia. This disagreement could also be due to the fact that the magnocellular system might work less via direct retinal-cortical pathways than via high-speed, retroactive information originating in the cortex and is not easily evaluated with current laboratory technology. ${ }^{73}$ A more indirect negative influence from a disturbance in processing attention might also be implicated since the magnocellular system is widely present in the posterior parietal cortex, which plays a well known role in visuospatial attention; ${ }^{74}$ specifically, the posterior parietal cortex plays a crucial role in the orientation of visuospatial attention.

\section{Visual attention and dyslexia}

Visual attention is the ability to quickly select the most relevant visual information. Its purpose is to choose which areas of the image to analyze first, with these areas being perceived as potentially more interesting. Visual attention reduces the amount of information that can be processed, and accelerates the entire vision process. "Selective" attention concerns "the ability to centralize gaze on the relevant information from among multiple stimuli located in the visual field while ignoring those not relevant to the performance of a task."75 "Divided" attention is defined as "the ability to respond to several visual stimuli simultaneously in order to perform two or more visual tasks at the same time." 77 The role assigned to the focalization of attention in the different reading models previously described justifies analysis of focalization in dyslexics. 
While phonological dysfunction appears to be central to the genesis of dyslexic disorders, it may be accompanied by visual-attention dysfunction in a large number of cases. ${ }^{35}$ This would be detectable through the analysis of an "attention window," defined by Bosse et al, ${ }^{9}$ as "the amount of orthographic information able to be treated at every step of reading." ${ }^{\prime 9}$ In practice, its clinical assessment is done by analyzing the visual attention span (EVA), which corresponds to the amount of distinct visual elements that can be processed simultaneously within a configuration of several components. ${ }^{76}$ As part of an assessment of reading skills, the measurement of EVA is performed by measuring the amount of separate letters that the patient is able to correctly name after a single and short (200 ms) fixation of a sequence of five consonants that have no semantic significance (the patient must name the letters he or she saw in the series NXKLR, for example - each letter having a well defined size and space, which separate it from its neighbors). The role of the EVA would be different depending on whether the word to be read is known (global reading mode) or new (analytical reading mode); a reduction in EVA would significantly disrupt global reading while the analytical mode would, up to a certain point, be more sensitive to phonological disturbance. Analysis of EVA in the dyslexic reader shows that the phonological deficit and visual-attention disorder are often dissociated, with EVA appearing as a second, distinct cognitive factor in the origin of dyslexia and equal (perhaps) to the input of the phonological component. ${ }^{9,76}$

A study of 68 dyslexic children revealed that the majority of dyslexics do not present this double deficit, with $60 \%$ having an isolated deficit either on phonological or visual attention, with a substantially equivalent proportion for each deficit. The remaining $40 \%$ have either a double deficit or none at all. ${ }^{9}$ The performance during the evaluation of EVA also seems to reflect the capabilities of reading words and pseudowords, regardless of phonological skills. This finding calls into question a number of principles used in speech therapy tests that primarily analyze reading profile tests to define the different types of dyslexia. EVA disturbances may play a role in the very particular nature of dyslexic saccades. ${ }^{77}$ The f-MRI studies in patients with an EVA deficit point to the existence of a bilateral parietal malfunction, involving notably the superior parietal lobule. ${ }^{78}$

\section{Spatial attention, spatial representation, and dyslexia}

The participation of the parietal cortex in spatial attention deficits of dyslexia might manifest itself at a supramodal level by affecting notably selective visual and spatial attention. ${ }^{79,80}$
In dyslexic children, the manifestations of visual and spatial attention deficits take on different forms. They may translate into deficits of distinction of target stimuli amongst distractive stimuli. ${ }^{81-84}$ They may also manifest as an increase in the amount of time necessary for the identification of visual stimuli. ${ }^{85}$ Attention deficits may also manifest as a more diffuse spatial distribution, with difficulties in focally orienting one's visual attention, ${ }^{86}$ or as an alteration of the processes used for the flexibility of attention. ${ }^{87}$

Spatial orientation is also affected in dyslexics. The distribution of spatial attention is in the form of a gradient, favoring the right side of a space. The attention allocated to the left side of a space is tenuous, while attention to the right is more pronounced. For example, during tasks requiring temporal judgment or during the illusion of the movement of lines, dyslexic adults present a preference for the right visual field. ${ }^{87}$ Similarly, adults with developmental dyslexia show better performances than controls in the right visual field versus the left. ${ }^{88}$ In tasks requiring flexibility of attention, dyslexic children have a reduced interference effect in the left visual field (left inattention), concomitant with an increased interference effect in the right visual field resulting from a difficulty in removing irrelevant information in the right visual field. ${ }^{89}$ The asymmetry of spatial orientation may be even more pronounced as to produce a veritable neglect of the left side of space, as illustrated by Stein et $\mathrm{l}^{60}$ in presenting the case of a dyslexic child who omits the entire left side of space when he was asked to complete a blank dial in the clock test.

Spatial attention affects not only the ability to detect stimuli, but also the ability to mentally represent these stimuli. In healthy subjects without neurological injury, the right hemispherical dominance of visual-spatial functions is responsible for a spontaneous bias for orientation of attention toward the left space, leading to an overrepresentation of the left side of space and underrepresentation of the right side of space, designated as pseudoneglect..$^{90}$ The line bisection test - which consists in its classic version, of indicating with a pencil mark the center of a line segment presented on a sheet of paper - is a simple and valuable tool for estimating spatial representation. Pseudoneglect is characterized by a bisection bias directed to the left. ${ }^{91}$ The preferred orientation of attention to the right in dyslexic children is responsible for a bias directed towards the right in manual and perceptual bisection tests. ${ }^{92-94}$ The low amplitude of this bias for the right led to the term "mini-neglect," which is in comparison to the high amplitude bias to the right found in neglect patients. ${ }^{95}$ Nevertheless, despite this low amplitude 
right-side bias, the presence of spatial cues at the extremities of lines allows dyslexic children to preserve analysis of spatial context suggesting an "inverse pseudo-negligence" rather than a "mini-neglect." The qualitative similarities in the performance of attention and in the representation between dyslexic children and neglect patients suggests a functional deficit in the right parietal cortex, which abolishes the right hemispherical dominance of visual-spatial functions in dyslexic children. ${ }^{96}$

\section{Visual therapy for dyslexia}

The treatment of dyslexia is currently based on speech therapy regimens. Scientific analysis of the results is inadequate with regard to the frequency and severity of this disorder. It seems that treatment is more successful when the rehabilitation is intensive and specifically adapted to the child's difficulties. Programs for intensive stimulus of phonological skills have been proposed. They have proven to be difficult to implement due to the constraints of organization in schools, and improving phonological skills is not followed by an automatic improvement in reading performance. ${ }^{97}$ The finding of multiple dysfunctions in the dyslexic ("constellation dys") often leads to reinforcement of speech therapy with additional therapies: psychomotor skills, psychology etc.

In the visual sphere, it is essential that all dyslexics receive comprehensive ophthalmological examinations, including cycloplegia, to uncover masked hyperopia as well as to perform a detailed analysis of ocular motility and accommodative power. All refractive disorders must be corrected since they may aggravate difficulties in decoding, and they can impede attention by excessively soliciting accommodation.

The improvement of visual capture of written language was initially oriented towards oculomotor rehabilitation with reeducation of convergence insufficiency when present, which is often the case. ${ }^{47,98}$ A literature review conducted in 2006 by Granet et a $^{99}$ has shown that this treatment improves comfort and reading time, but does not directly improve the possibilities of decoding and comprehension. ${ }^{98}$ Ocular motility recordings showing that the visual axes converge excessively sometimes, demonstrating the need for a study analyzing the dyslexic's divergence in order to best guide the possibilities for vergence therapy. ${ }^{56}$ The cost of these video-graphic techniques is the main obstacle to their use.

Orthoptic rehabilitation inspired by "behavioral vision therapy" is sometimes proposed when there are disturbances in saccades or in pursuit (the ability to visually locate and follow an object) in the dyslexic. No scientific study has shown the merits of this therapy which, in the absence of routine use of video-oculography, singularly video-oculography, fails primarily due to the lack of specific criteria for evaluation of disturbances of saccades and pursuit in the dyslexic. ${ }^{100}$ The American Academy of Ophthalmology recommended against this type of training in its report from 2011 due to the weakness of the statistical data found in various studies. This attitude, however, is highly controversial. First, the criteria are very difficult to implement due to the heterogeneity of the dyslexic population. Secondly, it is sometimes difficult to separate poor readers from dyslexics in the first stages of learning to read. ${ }^{101.102}$

Stein et $\mathrm{al}^{44}$ proposed to correct the effects of unstable binocular vision in the dyslexic by the use of monocular occlusion during reading. The study was conducted with a group of 143 dyslexic children, aged 7 to 11 years, with no known ophthalmologic problem but with unstable binocular control on the Dunlop test. All the children were asked to wear slightly tinted yellow glasses (in order to address the hypothetical presence of a disorder of the magnocellular system), and the left eye of 71 of the participants was occluded while reading or writing. After 3 months, the binocular control was stabilized for $59 \%$ of the children in the unilateral occlusion group compared to only $36 \%$ in the other group. This stabilization was accompanied by a significant improvement in reading ability (the reading delay was decreased by 9.4 months), which then continued at a slower pace for a total improvement of 16.1 months in the occluded group compared to 8 months for the group without occlusion (follow-up of 9 months).

Iovino et $\mathrm{al}^{103}$ evaluated the use of red and blue tinted glasses, which are thought to increase contrast and enhance the functioning of the magnocellular system. The study examined 60 subjects in the 8- to 18-year age range with no visual anomaly; only 15 of the participants were dyslexic while the other 15 were classified as reading-spellingarithmetic disabled. Of the remaining 30 children, half were arithmetic-disabled and the other half had an attention deficit/ hyperactivity disorder without learning disabilities. The advantage of this sampling was to introduce comorbidities to the study of the effect of colored overlays on dyslexics. All of the subjects had to do two reading tests using black letters: the Word Identification subtest of the Woodcock Reading Mastery Test-Revised ${ }^{104}$ (a word recognition task) and the Formal Reading Inventory ${ }^{105}$ (a reading comprehension task). The text was covered with either a red, blue, or no overlay. The blue overlay wavelengths ranged from $380 \mathrm{~nm}$ to $580 \mathrm{~nm}$ and had a peak wavelength of $480 \mathrm{~nm}$, whereas the 
red wavelengths ranged from $640 \mathrm{~nm}$ to $780 \mathrm{~nm}$ with a peak wavelength of $700 \mathrm{~nm}$. For the reading recognition test, no effects of overlays were found with any of the colors. For the reading comprehension test, almost $60 \%$ of the children showed slight to significant improvement. A contrast analysis was conducted to separate out the effect of each color. Iovino et $\mathrm{al}^{103}$ found that $57 \%$ of all of the children saw an increase in their performance with the blue filter, while 37\% presented a decrease in their score. When using the red filter, the contrast analyses revealed that the use of this overlay did not significantly affect reading comprehension accuracy, even though 13 of the 60 children presented a clear improvement in their performance. However, when the authors used the reading recognition latency as a covariate in the repeated measures model (in order to evaluate the effects of decoding ability on reading comprehension skills), the effect of both colors was not significant. The authors concluded that "there was no evidence that visual overlays had a beneficial, differential effect on reading skills in reading-spelling disabled children." 103

The use of tinted lenses was initially proposed in a much more personalized mode for the Irlen Syndrome (also known as visual stress, Meares-Irlen syndrome, and scotopic sensitivity syndrome), which could affect $15 \%$ of the general population and $45 \%$ of children with a learning disorder. ${ }^{106}$ Patients would then have impaired visual perception to certain wavelengths of light. These disturbances, undetectable by the usual visual examinations, would be responsible for a "visual stress" with difficulties of fixation, abnormal fatigue, migraines, and moodiness. ${ }^{107}$ The very existence of Irlen syndrome is debatable, even though a recent f-MRI study shows functional abnormalities in regions treating visual and sensory information. ${ }^{108}$ Treatment is based on individually prescribed colored filters, either tinted spectacle lenses or colored overlays, that filter wavelengths that are poorly supported by the patient as determined by personalized testing. Evaluation of this technique has yielded conflicting results and it is not available everywhere in the world. ${ }^{109}$ The American Academy of Pediatrics notes that the studies performed to investigate the condition are often of poor quality. Ritchie et al ${ }^{107}$ conducted the most recent assessment in 2011. It should be noted that at the outset, this test was performed on children judged to be below-average readers who had not undergone a common assessment that would have proven them to be dyslexic. The group included 57 children whose reading skill levels were assessed using the Wilkins Rate of Reading and the Gray Oral Reading tests. Orthoptic examination complemented these tests. The diagnosis of Irlen syndrome was made in 44 of 57 children (77\%). Children in this group performed the reading test twice with an overlay adapted to their cases, selected (if possible) from the complementary portion of the spectrum, and with a colorless overlay. Children free of signs of Irlen syndrome were evaluated under the same conditions, the color overlays being chosen to ensure that the two groups had homogenous color distributions. A mixed-design analysis of variance was performed on the Wilkins Rate of Reading Test scores, with the between-subject factor of group (non-Irlen/ Irlen) and the within-subject factor of the overlay condition. The main effect of the group was not significant. There was no significant effect of overlay condition or an interaction between the factors. The authors conclude that colored overlays, whether of the prescribed color or not, did not facilitate reading rate compared with a colorless overlay.

Postural treatment, also called "proprioceptive treatment," proposes suppression of the very low amplitude vertical heterophorias observed in dyslexics. ${ }^{110}$ This is accomplished using prisms of 1 to 3 diopters oriented toward the axis of action of the oblique muscles. Vertical heterophorias are considered to be the vertical component of cyclophorias secondary to hypotonia of the superior oblique muscles, their tonus being highly dependent on postural reflexes. The algorithm for the prescription of postural prisms is based on visual and postural clinical criteria. ${ }^{54}$ Prisms are complemented with orthopedic insoles, instructions concerning the best posture while reading, and exercises destined to regulate the function of various muscle groups. A double-blind study, with a group of 16 treated and 14 control dyslexics followed for 6 months, showed a significant improvement in global leximetric testing in reading regular words and irregular words, as well as in tests of orthographic decision making. On the other hand, there was no significant improvement with regard to all tests concerning phonological awareness. ${ }^{55}$ These results, obtained from a study of only 30 dyslexics, have yet to be confirmed.

One of the first additional studies, measuring postural constants during attention, suggested that the treatment might act by modifying the dyslexic's capacities for attention. ${ }^{111}$ In this study, the postural parameters of 27 dyslexics (12 untreated and 15 treated, with the postural regimen for 3 months; mean age: $11.6 \pm 2.1$ years, $12.5 \pm 1.5$ years, and $10.6 \pm 1.7$ years, respectively) were compared with 12 nondyslexic children. All of the children had to remain motionless on a force plate while either fixating on one point or performing a silent reading task (a Stroop test, which requires significant cognitive effort). The mean velocity 
of the center of pressure displacement was only increased in the reading task for the dyslexic group. For the treated children, in 13 of 15 patients, an inverse tendency was observed with a mean velocity similar to those observed for the control children. Other authors have reached different conclusions using a very similar protocol. ${ }^{112}$ It is possible that this difference is due to the fact that the study examined older dyslexics with postural characteristics closer to those of adults (age range of 14-17 years). Other researchers, in examining the effect of a dual task on postural control in dyslexic children, studied 18 dyslexic children (mean age $10.3 \pm 1.2$ years) who were compared with 18 nondyslexic children of similar ages, seemed to have confirmed that dyslexic children are significantly more unstable during the reading task compared with a simple reflex horizontal and vertical saccades task. ${ }^{113}$ This postural instability could indicate that such children lack the integration of multiple sensorimotor inputs.

A newer protocol on a large cohort (123 children) seems to confirm that, like auditory and visual sensory information, the integration of proprioceptive information is different in dyslexic children. ${ }^{5}$ Thirty dyslexic and 51 treated dyslexic children (3 months of treatment with low-power prisms cancelling small vertical heterophoria) were compared with 42 nondyslexic children. Two conditions were compared: co-85 Hz vibration at the ankles versus the absence of vibrations with, for each of the conditions, the use of two different attention tasks (ie, fixing a single point, or counting large or small stars within a range of stars of different sizes and drawn on a standard A4 sheet). Postural balance was recorded on a force platform. The results indicate that the average speed of the center of pressure in the presence of vibrations at $85 \mathrm{~Hz}$ (compared to the condition without vibration) is significantly increased in children with either treated or untreated dyslexia. This result is obtained regardless of the attention task requested. Without vibration, the attention performance of the treated group was similar to that of the control group, even though the performance was significantly degraded in the untreated group. These results suggest that the integration of proprioceptive signals during postural control as well as the attentional ability are both actually altered in children with dyslexia. The results also show that, during postural control, the attention ability of an individual with dyslexia rejoins the level of the normal reader after proprioceptive treatment.

Some physical characteristics of a text can play a role in the decoding used for reading. Zorzi et al have shown that for the Times Roman size 14 font, increasing the space between the letters to 2.7 points - which is associated with a proportional increase in the spaces between words and between lines - can significantly increase the reading speed of certain dyslexics. ${ }^{114}$ This help is easy to set up and can be very useful.

\section{Conclusion}

Dyslexia is a complex, multifaceted learning disorder that affects $5 \%$ to $10 \%$ of school-aged children. It is a pathology capable of definitively altering the personal and social futures of those afflicted. Many challenges still need to be overcome in order to define an effective treatment. Because of the heterogeneousness of the clinical aspects among dyslexic children, the evaluation of therapeutics is always very difficult and often results in suspicions that any improvements that are found may be due to placebo effects. The arrival of new explanatory theories and advances in neuroscience, particularly in regard to visual attention, provides an incentive for ophthalmologists to enter the world of multimodal cognition given the importance of the eye's visual input.

\section{Acknowledgment}

This work was supported by a grant of the 3Dys French Association.

\section{Disclosure}

The authors report no conflicts of interest in this work.

\section{References}

1. Quercia P. Ocular movements and reading: a review. J Fr Ophtalmol. 2010;33(6):416-423. French.

2. LaBuda MC, DeFries JC. Cognitive abilities in children with reading disabilities and controls: a follow-up study. J Learn Disabil. 1988; 21(9):562-566.

3. British Dyslexia Association. Dyslexia research information [webpage on the Internet]. Bracknell, UK: British Dyslexia Association; Available from: http://www.bdadyslexia.org.uk/about-dyslexia/furtherinformation/dyslexia-research-information-.html. Accessed. March 1, 2013.

4. Fawcett AJ, Nicolson RI, Dean P. Impaired performance of children with dyslexia on a range of cerebellar tasks. Ann Dyslexia. 1996; 46(1):259-283.

5. Quercia P, Demougeot L, Dos Santos M, Bonnetblanc F. Integration of proprioceptive signals and attentional capacity during postural control are impaired but subject to improvement in dyslexic children. Exp Brain Res. 2011;209(4):599-608.

6. Fletcher JM, Shaywitz SE, Shaywitz BA. Comorbidity of learning and attention disorders. Separate but equal. Pediatr Clin North Am. 1999;46(5):885-897, vi.

7. Manis FR, Seidenberg MS, Doi LM, McBride-Chang C, Petersen A. On the bases of two subtypes of developmental [corrected] dyslexia. Cognition. 1996;58(2):157-195.

8. Hutzler F, Wimmer H. Eye movements of dyslexic children when reading in a regular orthography. Brain Lang. 2004;89(1):235-242. 
9. Bosse ML, Tainturier MJ, Valdois S. Developmental dyslexia: the visual attention span deficit hypothesis. Cognition. 2007;104(2):198-230.

10. Vernet M, Kapoula Z. Binocular motor coordination during saccades and fixations while reading: a magnitude and time analysis. $J$ Vis. 2009;9(7):2

11. Gautier V, O'Regan JK, Le Gargasson JF. 'The-skipping' revisited in French: programming saccades to skip the article 'les'. Vision Res. 2000;40(18):2517-2531

12. Nuthmann A, Kliegl R. An examination of binocular reading fixations based on sentence corpus data. J Vis. 2009;29(5):31.1-28.

13. Reichle ED, Warren T, McConnell K. Using E-Z Reader to model the effects of higher level language processing on eye movements during reading. Psychon Bull Rev. 2009;16(1):1-21.

14. Reichle ED, Rayner K, Pollatsek A. Eye movement control in reading: accounting for initial fixation locations and refixations within the E-Z Reader model. Vision Res. 1999;39(26):4403-4411.

15. Drieghe D, Rayner K, Pollatsek A. Mislocated fixations can account for parafoveal-on-foveal effects in eye movements during reading. QJ Exp Psychol (Hove). 2008;61(8):1239-1249.

16. Aghababian V, Nazir TA. Developing normal reading skills: aspects of the visual processes underlying word recognition. J Exp Child Psychol. 2000;76(2):123-50.

17. MacKeben M, Trauzettel-Klosinski S, Reinhard J, Dürrwächter U, Adler M, Klosinski G. Eye movement control during single-word reading in dyslexics. JVis. 2004;14(5):388-402.

18. Morrison RE. Manipulation of stimulus onset delay in reading: evidence for parallel programming of saccades. J Exp Psychol Hum Percept Perform. 1984;10(5):667-682.

19. Reichle ED, Rayner K, Pollatsek A. The E-Z reader model of eyemovement control in reading: comparisons to other models. Behav Brain Sci. 2003;26(4):445-476.

20. Legge GE, Klitz TS, Tjan BS. Mr Chips: an ideal-observer model of reading. Psychol Rev. 1997;104(3):524-553.

21. Engbert R, Longtin A, Kliegl R. A dynamical model of saccade generation in reading based on spatially distributed lexical processing. Vision Res. 2002;42(5):621-636.

22. Millet $\mathrm{S}$. Médiation phonologique, accès lexical et controle oculomoteur en lecture [webpage on the Internet]. Available from: http://documents univ-lille3.fr/files/pub/www/recherche/theses/millet-sebastien/html/ these_body.html. Accessed January 1, 2013. French.

23. Cohen et al. The visual word form area: spatial and temporal characterization of an initial stage of reading in normal subjects and posterior split-brain patients. Brain. 2000;123(Pt 2):291-307.

24. Dehaene S, Le Clec'H G, Poline JB, Le Bihan D, Cohen L. The visual word form area: a prelexical representation of visual words in the fusiform gyrus. Neuroreport. 2002;13(3):321-325.

25. Dehaene S. Les Neurones de la Lecture. Paris: Edition Odile Jacob; 2007. French.

26. Brett M, Johnsrude IS, Owen AM. The problem of functional localization in the human brain. Nat Rev Neurosci. 2002;3(3):243-249.

27. Marinkovic K, Dhond RP, Dale AM, Glessner M, Carr V, Halgren E. Spatiotemporal dynamics of modality-specific and supramodal word processing. Neuron. 2003;38(3):487-497.

28. Stanovich KE, Siegel LS, Gottardo A. Converging evidence for phonological and surface subtypes of reading disability. J Educ Psychol. 1997;89(1):114-127.

29. Valdois S, Habib M, Cohen L. The reader brain: natural and cultural story. Rev Neurol (Paris). 2008;164 Suppl 3:S77-S82.

30. Valdois S, Bidet-Ildei C, Lassus-Sangosse D, et al. A visual processing but no phonological disorder in a child with mixed dyslexia. Cortex. 2011;47(10):1197-1218.

31. Handler SM, Fierson WM; for Section on Ophthalmology; Council on Children with Disabilities; American Academy of Ophthalmology; American Association for Pediatric Ophthalmology and Strabismus; American Association of Certified Orthoptists. Learning disabilities, dyslexia, and vision. Pediatrics. 2011;127(3): e818-e856.
32. Biscaldi M, Gezeck S, Stuhr V. Poor saccadic control correlates with dyslexia. Neuropsychologia. 1998;36(11):1189-1202.

33. Hawelka S, Gagl B, Wimmer H. A dual-route perspective on eye movements of dyslexic readers. Cognition. 2010;115(3):367-379.

34. Facoetti A, Zorzi M, Cestnick L, et al. The relationship between visuo-spatial attention and nonword reading in developmental dyslexia. Cogn Neuropsychol. 2006;23(6):841-855.

35. Valdois S, Bosse ML, Tainturier MJ. The cognitive deficits responsible for developmental dyslexia: review of evidence for a selective visual attentional disorder. Dyslexia. 2004;10(4):339-363.

36. Hutzler F, Kronbichler M, Jacobs AM, Wimmer H. Perhaps correlational but not causal: no effect of dyslexic readers' magnocellular system on their eye movements during reading. Neuropsychologia. 2006; 44(4):637-648.

37. De Luca M, Borrelli M, Judica A, Spinelli D, Zoccolotti P. Reading words and pseudowords: an eye movement study of developmental dyslexia. Brain Lang. 2002;80(3):617-626.

38. De Luca M, Di Pace E, Judica A, Spinell D, Zoccolotti P. Eye movement patterns in linguistic and non-linguistic tasks in developmental surface dyslexia. Neuropsychologia. 1999;37(12):1407-1420.

39. Bucci MP, Brémond-Gignac D, Kapoula Z. Poor binocular coordination of saccades in dyslexic children. Graefes Arch Clin Exp Ophthalmol. 2008;246(3):417-428.

40. Jainta S, Kapoula Z. Dyslexic children are confronted with unstable binocular fixation while reading. PLoS One. 2011;6(4):e18694.

41. Kirkby JA, Blythe HI, Drieghe D, Liversedge SP. Reading text increases binocular disparity in dyslexic children. PLoS One. 2011; 6(11):e27105.

42. Bigelow ER, McKenzie BE. Unstable ocular dominance and reading ability. Perception. 1985;14(3):329-335.

43. Cornelissen P, Bradley L, Fowler S, Stein JF. Covering one eye affects how some children read. Dev Med Child Neurol. 1992; 34(4): 296-304.

44. Stein JF, Richardson AJ, Fowler MS. Monocular occlusion can improve binocular control and reading in dyslexics. Brain. 2000;123(Pt 1): 164-170.

45. Lennerstrand G, Ygge J, Jacobson C. Control of binocular eye movements in normals and dyslexics. Ann N Y Acad Sci. 1993;682:231-239.

46. Stein JF, Riddell PM, Fowler S. Disordered vergence control in dyslexic children. Br J Ophthalmol. 1988;72(3):162-166.

47. Eden GF, Stein JF, Wood HM, Wood FB. Differences in eye movements and reading problems in dyslexic and normal children. Vision Res. 1994; 34(10):1345-1358.

48. Latvala ML, Korhonen TT, Penttinen M, Laippala P. Ophthalmic findings in dyslexic schoolchildren. Br J Ophthalmol. 1994;78(5):339-343.

49. Shainberg MJ. Vision therapy and orthoptics. Am Orthopt J. 2010;60:28-32.

50. Dusek WA, Pierscionek BK, McClelland JF. An evaluation of clinical treatment of convergence insufficiency for children with reading difficulties. BMC Ophthalmol. 2011;11:21.

51. Kapoula Z, Bucci MP. Postural control in dyslexic and non-dyslexic children. J Neurol. 2007;254(9):1174-1183.

52. Quercia P, Seigneuric A, Chariot S, et al. Ocular proprioception and developmental dyslexia. Sixty clinical observations. J Fr Ophtalmol. 2005;28(7):713-723. French.

53. Quercia P, Fourage R, Guillarme L, Marino A, Quercia M, Saltarelli S Traitement Proprioceptif et Dyslexie. Beaune:AF3dys EditionAF3dys@ neuf.fr.; 2008

54. Quercia P, Seigneuric A, Chariot S, Bron A, Creuzot-Garcher C, Robichon F. Proprioception changes induced by prismatic glasses wear in children suffering from developmental dyslexia. J Fr Ophtalmol. 2007;30(4):380-389. French.

55. Kapoula Z, Bucci MP, Jurion F, Ayoun J, Afkhami F, Brémond-Gignac D. Evidence for frequent divergence impairment in French dyslexic children: deficit of convergence relaxation or of divergence per se. Graefes Arch Clin Exp Ophthalmol. 2007;245(7): 931-936. 
56. Patel SS, Oğmen H, White JM, Jiang BC. Neural network model of short-term horizontal disparity vergence dynamics. Vision Res. 1997;37(10):1383-1399.

57. Stein J. The magnocellular theory of developmental dyslexia. Dyslexia. 2001;7(1):12-36.

58. Stein J, Talcott J, Walsh V. Controversy about the visual magnocellular deficit in developmental dyslexics. Trends Cogn Sci. 2000; 4(6):209-211.

59. Schulte-Körne G, Bruder J. Clinical neurophysiology of visual and auditory processing in dyslexia. Clin Neurophysiol. 2010; 121(11):1794-1809.

60. Livingstone MS, Rosen GD, Drislane FW, Galaburda AM. Physiological and anatomical evidence for a magnocellular defect in developmental dyslexia. Proc Natl Acad Sci U S A. 1994;88(18):7943-7947.

61. Walker KM, Hall SE, Klein RM, Phillips DP. Development of perceptual correlates of reading performance. Brain Res. 2006; 1124(1):126-141.

62. Galaburda AM, Menard MT, Rosen GD. Evidence for aberrant auditory anatomy in developmental dyslexia. Proc Natl Acad Sci US A. 1994;91(17):8010-8013.

63. Van Ingelghem M, van Wieringen A, Wouters J, Vandenbussche E, Onghena $\mathrm{P}$, Ghesquière $\mathrm{P}$. Psychophysical evidence for a general temporal processing deficit in children with dyslexia. Neuroreport. 2001;12(16):3603-3607.

64. Kuba M, Kubová Z, Kremlácek J, Langrová J. Motion-onset VEPs: characteristics, methods, and diagnostic use. Vision Res. 2007; 47(2):189-202.

65. May JG, Lovegrove WJ, Martin F, Nelson P. Pattern-elicited visual evoked potentials in good and poor readers. Clinical Vision Sciences. 1991;6:131-136.

66. Lehmkuhle S, Garzia R, Turner L, Hash T, Baro JA. A defective visual pathway in children with reading disability. $N$ Engl J Med. 1993; 328(14):989-996.

67. Reid AA, Szczerbinski M, Iskierka-Kasperek E, Hansen P. Cognitive profiles of adult developmental dyslexics: theoretical implications. Dyslexia. 2007;13(1):1-24

68. Eden GF, Stein JF, Wood HM, Wood FB. Temporal and spatial processing in reading disabled and normal children. Cortex. 1995; 31(3):451-468.

69. Keen AG, Lovegrove WJ. Transient deficit hypothesis and dyslexia: examination of whole-parts relationship, retinal sensitivity, and spatial and temporal frequencies. Vision Res. 2000;40(6):705-715.

70. Hari R, Valta M, Uutela K. Prolonged attentional dwell time in dyslexic adults. Neurosci Lett. 1999;271(3):202-204.

71. Rutkowski JS, Crewther DP, Crewther SG. Change detection is impaired in children with dyslexia. JVis. 2003;3(1):95-105.

72. Demb JB, Boynton GM, Best M, Heeger DJ. Psychophysical evidence for a magnocellular pathway deficit in dyslexia. Vision Res. 1998; 38(11):1555-1559.

73. Skottun BC. The magnocellular deficit theory of dyslexia: the evidence from contrast sensitivity. Vision Res. 2000;40(1):111-127.

74. Constantinidis C. Posterior parietal mechanisms of visual attention. Rev Neurosci. 2006;17(4):415-427.

75. Prado C, Dubois M, Valdois S. The eye movements of dyslexic children during reading and visual search: impact of the visual attention span. Vision Res. 2007;47(19):2521-2530.

76. Peyrin C, Lallier M, Démonet JF, et al. Neural dissociation of phonological and visual attention span disorders in developmental dyslexia: FMRI evidence from two case reports. Brain Lang. 2012; 120(3):381-394

77. Facoetti A, Lorusso ML, Paganoni P, et al. Auditory and visual automatic attention deficits in developmental dyslexia. Brain Res Cogn Brain Res. 2003;16(2):185-191.

78. Hari R, Kiesila P. Deficit of temporal auditory processing in dyslexic adults. Neurosci Lett. 1996;205(2):138-140.

79. Casco C, Tressoldi PE, Dellantonio A. Visual selective attention and reading efficiency are related in children. Cortex. 1998; 34(4): $531-546$.
80. Iles J, Walsh V, Richardson A. Visual search performance in dyslexia. Dyslexia. 2000;6(3):163-177.

81. Marendaz C, Valdois S, Walsh JP. Dyslexie développementale et attention visuo-spatiale. Annee Psychol. 1996;96:193-224.

82. Wright CM, Conlon EG, Dyck M. Visual search deficits are independent of magnocellular deficits in dyslexia. Ann Dyslexia. 2012;62(1): 53-69.

83. Buchholz J, Aimola Davies A. Attentional blink deficits observed in dyslexia depend on task demands. Vision Res. 2007;47(10): 1292-1302.

84. Facoetti A, Paganoni P, Lorusso ML. The spatial distribution of visual attention in developmental dyslexia. Exp Brain Res. 2000; 132(4):531-538.

85. Facoetti A, Lorusso ML, Paganoni P, Umiltà C, Mascetti GG. The role of visuospatial attention in developmental dyslexia: evidence from a rehabilitation study. Brain Res Cogn Brain Res. 2003; 15(2): 154-164.

86. Facoetti A, Turatto M. Asymmetrical visual fields distribution of attention in dyslexic children: a neuropsychological study. Neurosci Lett. 2000;290(3):216-218.

87. Hari R, Renvall H, Tanskanen T. Left minineglect in dyslexic adults. Brain. 2001;124(Pt 7):1373-1380.

88. Geiger G, Lettvin JY, Zegarra-Moran O. Task-determined strategies of visual process. Brain Res Cogn Brain Res. 1992;1(1):39-52.

89. Facoetti A, Molteni M. The gradient of visual attention in developmental dyslexia. Neuropsychologia. 2001;39(4):352-357.

90. Milner AD, Brechmann M, Pagliarini L. To halve and to halve not: an analysis of line bisection judgements in normal subjects. Neuropsychologia. 1992;30(6):515-526.

91. Jewell G, McCourt ME. Pseudoneglect: a review and meta-analysis of performance factors in line bisection tasks. Neuropsychologia. 2000;38(1):93-110.

92. Michel C, Bidot S, Bonnetblanc F, Quercia P. Left minineglect or inverse pseudoneglect in children with dyslexia? Neuroreport. 2011;22(2):93-96.

93. Waldie KE, Hausmann M. Right fronto-parietal dysfunction in children with ADHD and developmental dyslexia as determined by line bisection judgements. Neuropsychologia. 2010;48(12): 3650-3656.

94. Sireteanu R, Goertz R, Bachert I, Wandert T. Children with developmental dyslexia show a left visual "minineglect". Vision Res. 2005;45(25-26):3075-3082.

95. Halligan PW. Drawing attention to neglect - the contribution of line bisection. Psychologist. 1995;8(6):257-264

96. Lorusso ML, Facoetti A, Toraldo A, Molteni M. Tachistoscopic treatment of dyslexia changes the distribution of visual-spatial attention. Brain Cogn. 2005;57(2):135-142.

97. Rapport de l'Inserm 2007. Expertise collective sur dyslexie, dysorthographie et dyscalculie. Available from: http:/www.inserm. fr/content/.../dyslexie_dysorthographie_dyscalculie.pdf. Accessed April 17, 2013.

98. Convergence Insufficiency Treatment Trial Study Group. Randomized clinical trial of treatments for symptomatic convergence insufficiency in children. Arch Ophthalmol. 2008;126(10):1336-1349.

99. Granet DB, Castro EF, Gomi CF. Reading: do the eyes have it? Am Orthopt J. 2006;56(1):44-49.

100. Metzger RL, Werner DB. Use of visual training for reading disabilities: a review. Pediatrics. 1984;73(6):824-829.

101. Beauchamp GR. Optometric vision training. Pediatrics. 1986; 77(1):121-124.

102. Rawstron JA, Burley CD, Elder MJ. A systematic review of the applicability and efficacy of eye exercises. J Pediatr Ophthalmol Strabismus. 2005;42(2):82-88.

103. Iovino I, Fletcher JM, Breitmeyer BG, Foorman BR. Colored overlays for visual perceptual deficits in children with reading disability and attention deficit/hyperactivity disorder: are they differentially effective? J Clin Exp Neuropsychol. 1998;20(6):791-806. 
104. Woodcock RW. Woodcock reading mastery tests-revised normative update (WRMT-R/NU). Circle Pines, MN: American Guidance Service. 1998.

105. Radencich MC. Test review: Gray oral reading tests: revised formal reading inventory. Journal of Reading. 1996;30(2):136-139.

106. Solan HA, Richman J. Irlen lenses: a critical appraisal. J Am Optom Assoc. 1990;61:789-796.

107. Ritchie SJ, Della Sala S, McIntosh RD. Irlen colored overlays do not alleviate reading difficulties. Pediatrics. 2011;128(4):e932-e938.

108. Chouinard BD, Zhou CI, Hrybouski S, Kim ES, Cummine J. A functional neuroimaging case study of Meares-Irlen syndrome/ visual stress (MISViS). Brain Topogr. 2012;25(3):293-307.

109. Solan HA. An appraisal of the Irlen technique of correcting reading disorders using tinted overlays and tinted lenses. J Learn Disabil. 1990;23(10):621-626.
110. Garrigues B. Anomalies de la localisation spatiale visuelle chez l'enfant dyslexique. Etude préliminaire. Posturologie clinique. Dysfonction motrices et cognitives. Paris, France: Masson ed; 2007:71-75. French.

111. Vieira S, Quercia P, MichelC, Pozzo T, Bonnetblanc F. Cognitive demands impair postural control in developmental dyslexia: a negative effect that can be compensated. Neurosci Lett. 2009;462(2):125-129.

112. Kapoula Z, Matheron E, Demule E, Fauvel C, Bucci MP. Postural control during the Stroop test in dyslexic and non dyslexic teenagers. PLoS One. 2011;6(4):e19272.

113. Legrand A, Bui-Quoc E, Doré-Mazars K, Lemoine C, Gérard CL, Bucci MP. Effect of a dual task on postural control in dyslexic children. PLoS One. 2012;7(4):e35301.

114. Zorzi M, Barbiero C, Facoetti A, et al. Extra-large letter spacing improves reading in dyslexia. Proc Natl Acad Sci U S A. 2012; 109(28):11455-11459.
Clinical Ophthalmology

\section{Publish your work in this journal}

Clinical Ophthalmology is an international, peer-reviewed journal covering all subspecialties within ophthalmology. Key topics include: Optometry; Visual science; Pharmacology and drug therapy in eye diseases; Basic Sciences; Primary and Secondary eye care; Patien Safety and Quality of Care Improvements. This journal is indexed on

Submit your manuscript here: http://www.dovepress.com/clinical-ophthalmology-journal

\section{Dovepress}

PubMed Central and CAS, and is the official journal of The Society of Clinical Ophthalmology (SCO). The manuscript management system is completely online and includes a very quick and fair peer-review system, which is all easy to use. Visit http://www.dovepress.com/ testimonials.php to read real quotes from published authors. 